\title{
Determinants of Adherence to the Recommended COVID-19 Prevention and Control Guidelines by Small Scale Retail Shop Operators in Rural Parts of Siaya County, Kenya
}

\author{
Peter Omemo*, and Job Wasonga \\ Department of Public Health, Maseno University, Kenya
}

*Corresponding author: Peter Omemo, Department of Public Health, Maseno University, Kenya, E-mail: omemopeter@gmail.com

Received: 28 Jul, 2020 | Accepted: 21 Aug, 2020 | Published: 27 Aug, 2020

Citation: Omemo P, Wasonga J (2020) Determinants of Adherence to the Recommended COVID-19 Prevention and Control Guidelines by Small Scale Retail Shop Operators in Rural Parts of Siaya County, Kenya. J Epidemiol Public Health Rev 5(3): dx.doi.org/10.16966/24718211.198

Copyright: (C) 2020 Omemo P, et al. This is an open-access article distributed under the terms of the Creative Commons Attribution License, which permits unrestricted use, distribution, and reproduction in any medium, provided the original author and source are credited.

\section{Abstract}

Introduction: In order to prevent and control the spread of COVID-19 in Kenya the Ministry of Health (MoH) issued unprecedented guidelines to be followed by all citizens. Adherence to the MoH COVID-19 prevention and control guidelines in rural areas is generally a function of the residents' knowledge, attitude, and practices (KAP). Evidence shows that public knowledge is important in tackling pandemics.

Objective: The overall objective of this study was to assess the determinants of adherence to the COVID-19 prevention and control guidelines by the rural small scale shop operators (SSSOs) in Siaya County, Kenya.

Method: This is a cross sectional survey conducted in sixteen randomly selected market centres across Siaya County in May, 2020. The SSSOs were identified using a systematic random sampling technique. One hundred and seventy two rural SSSOs were requested to answer simple semistructured questions posed by the enumerators. The questionnaire assessed demographic characteristics, knowledge, attitude, and practice of the rural SSSOs toward COVID-19 prevention and control. Data were analysed using the Statistical Package for the Social Sciences (SPSS), version 26. Descriptive analysis focused on frequencies and percentages while chi-square test was applied to determine the differences between groups for selected study variables.

Result: The response rate was $100 \%$ (172) with male being $71.5 \%(123)$ and female $28.5 \%(49)$. Majority, that is $32.6 \%$ (56) of the SSSOs were in the age group, between 2 s1-25. About $32.6 \%(56)$ had poor knowledge of COVID-19; $\left(\chi^{2}(4 \mathrm{~N}=172)=25.965, p=.000\right)$, while only $12.2 \%(21)$ had good knowledge. About $40.7 \%(70)$ of the respondents had poor attitude $\left(\chi^{2}(4, N=172)=103.756, p=.000\right)$ towards COVID-19; equally, 33.1\% (57) had poor practice $\left(\chi^{2}(3, N=172)=13.814, p=.000\right)$.

Conclusion: The rural SSSOs in Siaya County have basic awareness about COVID-19 which is not translated into the knowledge about the cause prevention and control of the disease. Interventions aimed at improving the KAP of the rural SSSOs should be undertaken in order to enhance adherence to the COVID-19 prevention and control guidelines. This will also assist in cascading the right COVID-19 information in the rural villages across the County.

Keywords: Adherence; COVID-19; Control guidelines

\section{Introduction}

Corona virus disease 2019 (COVID-19) is an acute respiratory infection caused by severe acute respiratory syndrome corona virus 2 (SARS-CoV-2). SARS-CoV-2 belongs to the Sarbecovirus subgenus of the Coronaviridae family, and is the seventh corona virus known to infect humans [1].

The WHO first declared COVID-19 to be a public health emergency of international concern on 30 January 2020 and subsequently declared it a pandemic in March 2020. The first confirmed case in Kenya was reported on $13^{\text {th }}$ March 2020 and the government imposed a lockdown over the whole country in the same month [1] It is thought that human transmission occurs via respiratory droplets produced when a person sneezes or coughs. Current estimates of the incubation period range from 1 to 14 days, according to the World Health Organization [1]. The average incubation period is currently estimated to be 5 days. Transmission can occur during the incubation period. The most common clinical presentation is that of a respiratory infection with a symptom severity ranging from a mild common cold-like illness (estimated $80 \%$ of cases), to a severe viral pneumonia leading to acute respiratory distress syndrome that is potentially fatal [2]. It has been established that people can possibly get COVID-19 by 
touching an infected object or surface "and then touching their own mouth, nose, or possibly their eyes". As a good hygiene practice, people are advised to wash their hands after touching surfaces in public places or handling objects e.g., money, etc [3].

The Ministry of health $(\mathrm{MoH})$, Kenya rolled out advertisements in both print and electronic media urging the citizens to follow COVID-19 basic infection prevention guidelines as per WHO protocol [4] which are; hand hygiene; that is, frequent hand washing with soap and water or alcohol based sanitizer, respiratory hygiene; i.e., consistent use of face mask in public settings or sneezing on elbow, keeping a safe distance; at least 2 metres from other people and not touching the face especially mouth, nose and eyes. Despite the unprecedented national measures put in place by the Kenya government to prevent and control the spread of COVID-19, the success or failure of these efforts is largely dependent on public behavior [5]. Adherence is likely to be influenced by the public's knowledge and attitude and practice towards COVID-19. Evidence shows that public knowledge is important in tackling pandemics $[5,6]$. By assessing public awareness and knowledge about the corona virus, deeper insights into existing public perception and practices can be gained, thereby helping to identify attributes that influence the public in adopting healthy practices and responsive behavior [7]. Wearing a face mask should be considered, especially when visiting crowded busy places, such as market centres, shopping centres, public transport etc., or for those working in closed workplaces which involve physical proximity to many other people (such as shopkeepers, etc.) [8]. It is unclear to what extent COVID-19 will affect the rural population in Kenya since COVID-19 is an emerging, rapidly evolving situation. The pandemic calls for a new way of life which the rural folk will have to learn and adhere to. We thus, conducted this study with the overall objective of assessing the determinants of adherence to the COVID-19 prevention and control guidelines by the rural SSSOs in Siaya County, Kenya. We applied the hypothesis that there was no significance difference in the number of rural SSSOs with good and poor knowledge towards prevention and control of COVID-19.

\section{Materials and Methods}

This study was conducted using a cross-sectional survey of the small scale retail shop operators in the rural parts of Siaya County, Kenya between 10th and $25^{\text {th }}$ May, 2020. A sample size of 172 was calculated using Krejcie and Morgan tables for sample size determination [9]. A questionnaire was developed by the authors, according to Centers for Disease Control and guidelines [10]. The independent variables were sociodemographic characteristics of the respondents, while the dependent variables were the knowledge, attitude and practices of the respondents towards COVID-19.

\section{Knowledge}

Knowledge of the respondents was measured as; cause, transmission, prevention, signs and symptoms of COVID-19 using a five-point Likert scale. The rural SSSOs were asked to respond to knowledge items as either true or false, with an additional "don't know" option with regard to COVID-19. Incorrect or uncertain (don't know) responses were given a score of zero, and correct answers were assigned a score of one. The total score for knowledge questions ranged from 0 to 21 , with high scores (19-21) indicating very good knowledge of COVID-19, and low score (0-9) rated very poor knowledge. Meanwhile 10-12 correct responses was rated poor, 13-15 being moderate, 16-18 good.

\section{Attitude}

This was measured using the disposition and inclination of the respondent towards COVID-19. The participants' attitude towards COVID-19, was assessed using a five-point Likert scale i.e. $1=$ strongly disagree, $2=$ disagree, $3=$ undecided, $4=$ agree, and $5=$ strongly agree. Scores were calculated by averaging respondents' answers to the five statements. Total scores range was 1 to 21 , with high average of correct scores indicating very good attitude. Items were evaluated for internal reliability; using Cronbach's a coefficient at 0.81 .

\section{Practices}

The respondents' practices were assessed by asking the questions which required "yes" or "no" answer. A score of one was given to answers that reflected good practice, and a score of zero was given for wrong practice or wrong answer. The responses were given a code range of between 1 and 5 and scores aggregate range was between 1 to 21 . For instance $1=$ very poor, if the total correct score range for the variable was 7-9; $2=$ poor, if the total correct score range was between $10-12 ; 3=$ moderate, if the total correct score was $13-15 ; 4=$ good, if the total correct score was $16-18$ and $5=$ very good, if the total correct score was between 19-21.

\section{Statistical analysis}

Data were analysed using the Statistical Package for the Social Sciences (SPSS), version 26. Socio demographic data was presented using descriptive analysis which focused on frequencies and percentages the variables were presented in tables. A chi-square test was applied to determine the differences between groups for selected study variables. The statistical significance level was set at $\mathrm{p}<0.05$. The measurement criterion is summarized in Appendix.

\section{Results}

\section{Distribution of the respondents by gender}

A total of $71.5 \%$ (123) of respondents were males while $28.5 \%$ (28.5) were female. As shown in figure1.

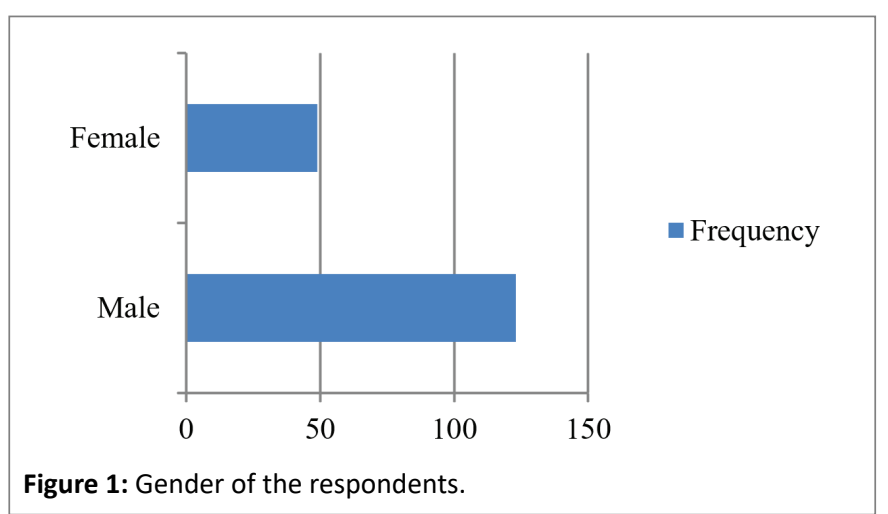

Figure 1: Gender of the respondents.

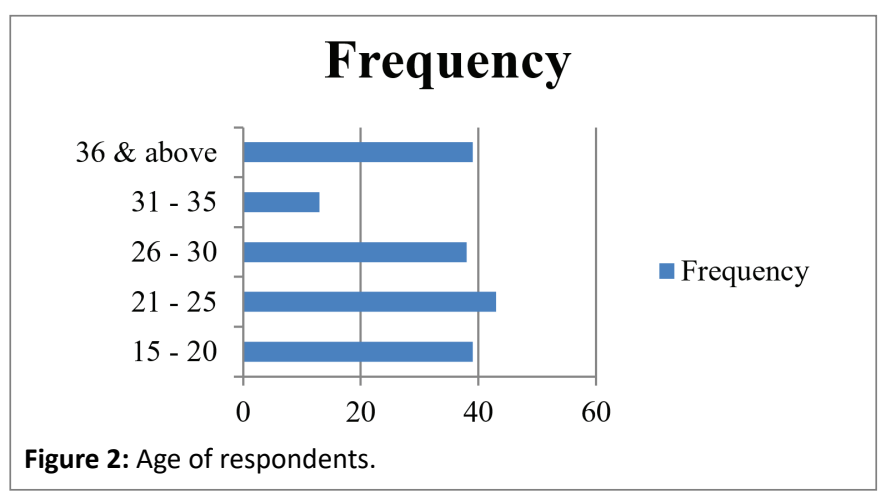




\section{Distribution of respondents by their age bracket}

Twenty five percent (43) of respondents were aged 21-25, the age group 15-20 (22.7\%) of them were those above 36 (22.7\%), 26-30 years were (22.1\%), but only ( $7.6 \%)$ of respondents were aged $31-35$ years as shown in figure 2 below.

\section{Status of knowledge of COVID-19 in Siaya county}

The results showed that $32.6 \%$ (56) of the rural small scale shop operators in Siaya County had poor knowledge of COVID-19, while $12.2 \%$ had good knowledge (Table1). The data was further tested using chi-square $\left(\chi^{2}\right)$ to determine if frequencies presented were significantly different. The null hypothesis that, there was no significant difference in the number of shopkeepers with good and poor knowledge towards COVID-19 in Siaya County was tested to generate a chi square test of goodness of fit for knowledge of COVID-19 by the shopkeepers. The result was that; $\chi^{2}(4, N=172)=25.965, p=0.000$ which led to the rejection of the null hypothesis.

Hol=fokng=fekng. (Where Kng denotes knowledge group).

\section{Attitude towards control and prevention of COVID-19}

The results showed that $40.7 \%$ (70) of the shopkeepers had poor attitude towards prevention and control of COVID-19 while 7\% (12) of the shopkeepers had good attitude towards COVID-19 prevention and control. The data was further tested using chi square to determine if the frequencies presented were significantly different. The null hypothesis that, there was no significant difference in the number of shopkeepers with good and poor attitude towards COVID-19 in Siaya County was tested. Table 2 shows the results of chi square test

Table 1: Knowledge of shopkeepers towards prevention and control of COVID-19 in Siaya County.

\begin{tabular}{|l|c|c|c|c|c|c|}
\hline \multicolumn{7}{|c|}{ Knowledge of Shopkeepers towards control and prevention of } \\
COVID-19 \\
\hline & Very good & Good & Moderate & Poor & Very poor & Total \\
\hline Count & 21 & 30 & 43 & 56 & 22 & 172 \\
\hline Percent & 12.2 & 17.4 & 25 & 32.6 & 12.8 & 100 \\
\hline Variable & $\mathrm{N}$ & $\chi^{2}$ & df & Sig. & Decision & \\
\hline $\begin{array}{l}\text { Status of } \\
\text { knowledge }\end{array}$ & 172 & 25.965 & 4 & .000 & Reject Ho1 & \\
\hline
\end{tabular}

Note: 0 cells $(0.0 \%)$ expected frequencies less than 5 . The minimum expected cell frequency was $25.965 . \chi^{2}(.05,4)=9.49$.

Table 2: Attitude of shopkeepers towards prevention and control of COVID-19.

\begin{tabular}{|l|c|c|c|c|c|c|}
\hline \multicolumn{7}{|c|}{ Attitude of shopkeepers towards prevention and control of COVID-19 } \\
\hline & Very good & Good & Moderate & Poor & Very poor & Total \\
\hline Count & 1 & 12 & 60 & 70 & 29 & 172 \\
\hline Percent & 0.6 & 7.0 & 34.9 & 40.7 & 16.9 & 100 \\
\hline Variable & $\mathrm{N}$ & $\chi^{2}$ & $\mathrm{df}$ & Sig. & Decision & \\
\hline $\begin{array}{l}\text { Status of } \\
\text { knowledge }\end{array}$ & 172 & 103.756 & 4 & 0.000 & Reject Ho2 & \\
\hline
\end{tabular}

Note: 0 cells $(0.0 \%)$ have expected frequencies less than 5 . The minimum expected cell frequency is $103.756 \chi^{2}(0.05,4)=9.49$. of goodness of fit for knowledge of COVID-19 by the shopkeepers. It shows that; $\chi^{2}(4, \mathrm{~N}=172)=103.756, \mathrm{p}=.000$. Ho2: fo Atg=fe Atg. (Where Atg denotes attitude group).

\section{Practice towards control and prevention of COVID-19}

The results showed that $33.1 \%$ (57) of the shopkeepers had poor practices, while $14 \%$ had good practices towards prevention and control of COVID-19 as shown in table 3. The hypothesis that there was no significant different in the number of shopkeepers with poor and good practices towards prevention and control of COVID-19 was Pg. (Where Pg denotes subjected to a chi-square test to determine if the frequencies presented were significantly different. Thus; Ho3: fo $=$ fe practices group). The results of Chi square test of goodness of fit on practices of the rural SSSOs towards prevention and control of COVID-19 showed that; $\chi^{2}(3, \mathrm{~N}=172)=13.814, \mathrm{p}=0.003$.

\section{Discussion}

The COVID-19 has been declared a Public Health Emergency of International Concern by the WHO and the virus has now spread to many countries around the globe. While a lot is still unknown about the virus that causes COVID-19, we do know that it is transmitted through direct contact with respiratory droplets of an infected person (generated through coughing and sneezing). Individuals can also be infected from touching surfaces contaminated with the virus and touching their face (e.g., eyes, nose and mouth). While COVID-19 continues to spread it is important that citizens take action to prevent further transmission, reduce the impacts of the outbreak and support control measures.

Hitherto, there is no proven effective vaccine for COVID-19. Governments are mainly relying on public health guideline measures issued by WHO to prevent and control the spread of the disease. This indicates the necessity of all citizens to adhere to preventive and control guidelines.

In Kenya, the government has conducted an intensive COVID-19 awareness campaign via print media, television and various vernacular radio stations in order to reach the general public.

However, our findings indicate that most SSSOs in rural parts of Siaya County, Kenya had poor knowledge about COVID-19. A small proportion (29.6\%) was aware of the transmission, prevention, signs and symptoms of the disease. Nevertheless, approximately half of the respondents were oblivious of social distancing or the need to wear face masks while serving their customers. These results agree with other findings that suggest people tend to express anxiety and panic only during early stages of a pandemic [11]. These findings are

Table 3: Practices of shopkeepers towards prevention and control of COVID-19.

\begin{tabular}{|l|c|c|c|c|c|c|}
\hline \multicolumn{6}{|c|}{ Practices of shopkeepers towards prevention and control of COVID-19 } \\
\hline & Very good & Good & Moderate & Poor & Very poor & Total \\
\hline Count & 0 & 24 & 49 & 57 & 42 & 172 \\
\hline Percent & 0.0 & 14.0 & 28.5 & 33.1 & 24.4 & 10 \\
\hline Variable & $\mathrm{N}$ & $\chi^{2}$ & $\mathrm{df}$ & Sig. & Decision & \\
\hline $\begin{array}{l}\text { Status of } \\
\text { practices }\end{array}$ & 172 & 13.814 & 3 & .003 & Reject Ho3 & \\
\hline
\end{tabular}

Note: 0 cells $(.0 \%)$ have expected frequencies less than 5 . Minimum expected cell frequency is $43 . \chi 2(0.05,3)=7.82$. 
Appendix 1: Summary of Measurement Criteria.

\begin{tabular}{|c|c|c|c|c|c|c|}
\hline Variable & Indicator & Score & Rating & Code & Level of measurement & Analysis method \\
\hline \multirow{5}{*}{ Knowledge } & What is COVID-19? & $0-9$ & Very poor & 1 & Interval & Chi Square \\
\hline & What are its symptoms? & $10-12$ & Poor & 2 & & \\
\hline & How does Corona Spread? & $13-15$ & Moderate & 3 & & \\
\hline & What is the treatment? & $16-18$ & Good & 4 & & \\
\hline & Who's most at risk & $19-21$ & Very good & 5 & & \\
\hline \multirow{5}{*}{ Attitude } & Disposition & $1-9$ & Very poor & 1 & Interval & Chi Square \\
\hline & Orientation & $10-12$ & Poor & 2 & & \\
\hline & Inclination & $13-15$ & Moderate & 3 & & \\
\hline & & $16-18$ & Good & 4 & & \\
\hline & & $19-20$ & Very good & 5 & & \\
\hline \multirow{6}{*}{ Practices } & Adherence & $1-9$ & Very poor & 1 & Interval & Chi Square \\
\hline & Hygiene & $10-12$ & Poor & 2 & & \\
\hline & Hand washing & $13-15$ & Moderate & 3 & & \\
\hline & & $11-12$ & & 4 & & \\
\hline & & $16-18$ & Good & 4 & & \\
\hline & & $19-20$ & Very good & 5 & & \\
\hline
\end{tabular}

also consistent with other studies which showed that the male were significantly less likely to take preventive and protective measures than women [12]. Conversely, there is significant difference in the number of SSSOs with poor and good knowledge towards prevention and control of COVID-19, hence, our study hypothesis that there was no significance difference in the number of SSSOs with good and poor knowledge towards prevention and control of COVID-19 was rejected. With regard to attitude and practice, the SSSOs generally showed a poor attitude toward COVID-19. Approximately $40.7 \%$ did not agree that wearing a face mask is one way of preventing transmission or contracting the disease. The SSSOs risk perception concurs with finding by $[7,8]$. However, the high number of SSSOs with poor attitude could be attributed to their poor knowledge about the disease. This finding agrees with observations by [12], that poor knowledge impedes people's perception of a disease risk.

\section{Conclusion}

The findings from this study may be useful to the Siaya County health authorities in identifying strategies that will reinforce the KAP of the rural population towards COVID-19 prevention and control. Small scale shop operators in rural areas are an important population since they interact with many customers of all age groups on a daily basis and there KAP may impede or flare up COVID-19 transmission. Presumably, by assessing peoples KAP towards the corona virus, deeper insights into the determinants of adherence to COVID-19 prevention and control guidelines by the population can be gained.

\section{Competing Interests}

The authors declare no competing interests.

\section{Authors' Contributions}

Omemo Peter prepared the initial manuscript. Job Wasonga did the critical review of the paper. All authors have read and approved the final version of the manuscript.

\section{References}

1. World Health Organization (2020) Coronavirus disease 2019 (COVID-19) Situation Report-38. Geneva, Switzerland.

2. Shereen MA, Khan S, Kazmi A, Bashir N, Siddique R (2020) COVID-19 infection: Origin, transmission, and characteristics of human corona viruses. J Adv Res 24: 91-98.

3. World Health Organization (2020) Responding to community spread of COVID-19. Geneva, Switzerland.

4. World Health Organization (2020) Advice on the use of masks in the context of COVID-19: Interim guidance, 6 April 2020. Geneva, Switzerland.

5. Chirwa GC (2020) "Who knows more, and why?" Explaining socio economic related inequality in knowledge about HIV in Malawi. Sci African 7: e00213.

6. Chirwa GC, Sithole L, Jamu E (2019) Socio-economic Inequality in Comprehensive Knowledge about HIV in Malawi. Malawi Med J 31: 104-111.

7. Podder D, Paul B, Dasgupta A, Bandyopadhyay L, Pal A, et al. (2019) Community perception and risk reduction practices toward malaria and dengue: A mixed-method study in slums of Chetla, Kolkata. Ind J Public Health 63:178-185. 
8. Güner R, Hasanoğlu I, Aktaş F (2020) COVID-19: Prevention and control measures in community. Turk J Med Sci 50: 571-577.

9. Krejcie RV, Morgan DW (1970) Determining Sample size for Research Activities. Educ Psychol Meas 30: 607-610.

10. Centers for Disease Control and Prevention (2020) Corona virus Disease 2019. Unites States of America.

11. Aldowyan N, Abdallah AS, El-Gharabawy R (2017) Knowledge, Attitude and Practice (KAP) Study about Middle East Respiratory Syndrome Corona virus (MERS-CoV) among Population in Saudi Arabia. Int Arch Med 10: 1-12.

12. Leung GM, Lam T-H, Ho L-M, Ho S-Y, Chan BHY, et al. (2003) The impact of community psychological responses on outbreak control for severe acute respiratory syndrome in Hong Kong. J Epidemiol Community Health 57:857-863. 